\title{
EDITORIAL
}

\section{CELEBRANDO EL CUADRAGÉSIMO ANIVERSARIO}

Desde 1974, en forma ininterrumpida, la Revista Chilena de Derecho ha sido uno de los principales medios de difusión académica de la Facultad de Derecho de la Pontificia Universidad Católica de Chile. Como tal, los resultados de la investigación científica que se publican en sus páginas responden a las necesidades de la comunidad jurídica nacional e internacional, siempre con el afán de difundir los permanentes avances de nuestra ciencia. Así entonces, a lo largo de un camino que suma ya cuarenta años, la Revista Chilena de Derecho se ha transformando paulatinamente en un referente obligado para la comunidad vinculada a los estudios dogmáticos del Derecho, llegando, también, a convertiste en una de las grandes realizaciones para todos quienes formamos parte de Derecho UC.

Nuestro orgullo proviene del esfuerzo colectivo que ha significado para nuestra Facultad construir una obra tan perdurable y significativa como la Revista Chilena de Derecho y que hoy se ve recompensado por una serie de reconocimientos que nos demuestran que un trabajo constante, potenciado con los aportes de la comunidad científica, rinde sus frutos, y en abundancia. Como Decano de la Facultad de Derecho UC, me parece necesario destinar unas palabras para recalcar la importancia de esta publicación y dar un meritorio cierre a un año de reconocimientos y avances.

En abril de 2013, la Academia Chilena de Ciencias Sociales, Políticas y Morales entregó un reconocimiento a la Revista por su dilatada trayectoria y servicio a la comunidad científico-jurídica del país. Esto fue sin duda un motivo de orgullo, tanto por el prestigio de quien entregaba la distinción, así como por el galardón que coronaba tan esmerada labor.

En materia de convenios internacionales, la Revista Chilena de Derecho suscribió un acuerdo con HeinOnline, una de las bases de datos para investigación jurídica más importantes a nivel mundial. Esto, sumado a la inclusión en el año 2012 en la base de datos de JStor y la posterior indexación en Web of Science (ex ISI), concluyen un exitoso proceso que coloca a la Revista Chilena de Derecho en un sitial privilegiado, ofreciendo asimismo una importante vitrina para nuestros autores.

Por último, se llevó a cabo en nuestra Facultad un encuentro de revistas jurídicas de diversas instituciones de educación superior, así como de las distintas revistas académicas que portan el sello UC. Este exitoso encuentro permitió acercar distintas realidades editoriales, así como también promover un fructífero diálogo con las autoridades de nuestra universidad y con representantes de CONICYT y SciELO, para un análisis de los desafíos futuros para el mundo editorial.

Hoy, ya cerrando nuestra celebración, podemos decir que la Revista Chilena de Derecho ha alcanzado una etapa madura, en que la alta valoración que existe sobre ella por parte del mundo científico se conjuga con los estándares de excelencia que cumplen los autores que en ella publican. Estamos muy satisfechos de contar con un acervo tan útil y eficaz, pero también sabemos que los desafíos futuros demandarán mayor trabajo de parte de todos quienes somos parte de nuestra Facultad. Hace ya 40 años, con pocos recursos, se 
Editorial

inició esta empresa y hoy, mientras la Pontificia Universidad Católica de Chile ha ascendido en forma sostenida entre los rankings internacionales hasta convertirse en la mejor de Sudamérica, en una época en que nuestra Facultad también ha sido reconocida por su liderazgo en el continente, es indispensable unir las voces de Derecho UC para desearle a nuestra querida Revista Chilena de Derecho las mejores venturas y celebrar orgullosamente sus cuatro décadas de esfuerzos, desafíos y grandes logros. Que sean muchos años más, y a seguir hacia adelante.

Roberto Guerrero ValenZuela

Decano, Facultad de Derecho

Pontificia Universidad Católica de Chile. 